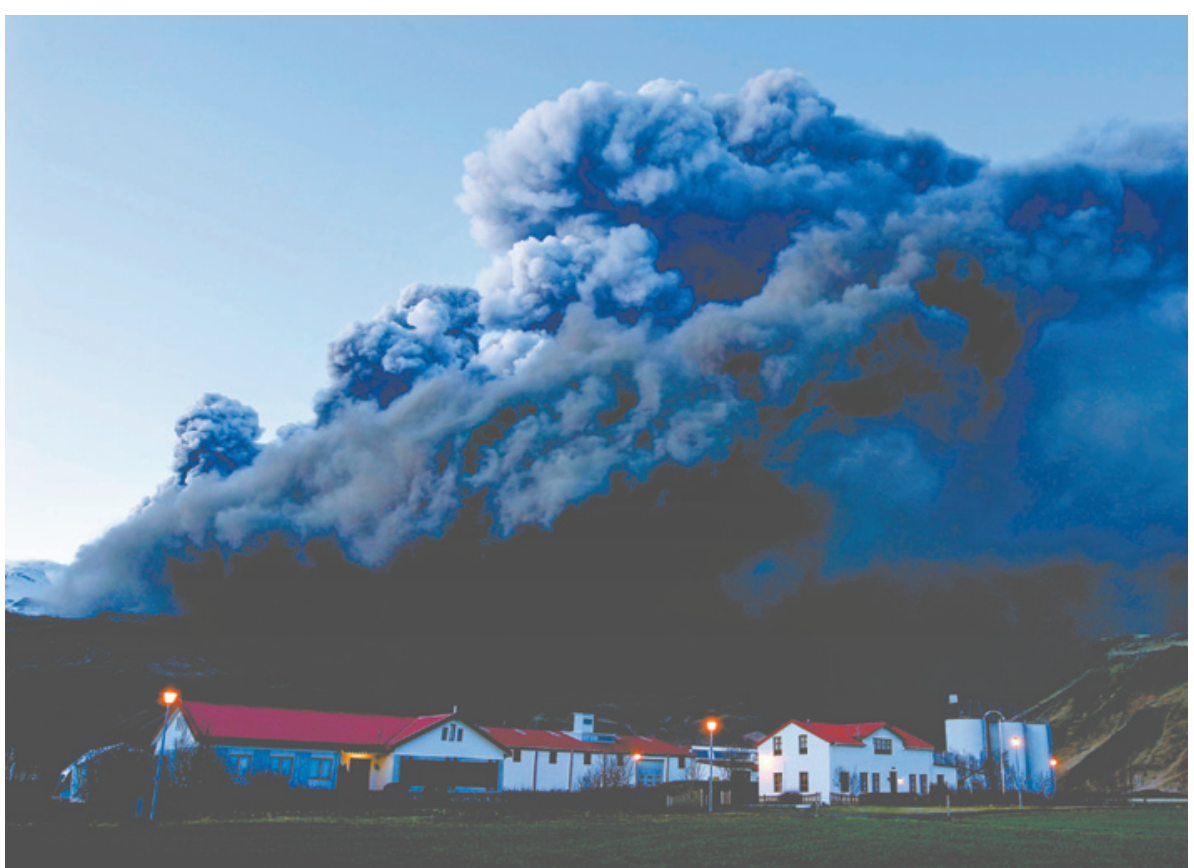

The 2010 eruption of Eyjafjallajökull grounded aircraft with engines that are vulnerable to volcanic ash.

ATMOSPHERIC SCIENCE

\title{
Volcanic-ash sensor to take flight
}

\section{Researchers will fly jet towards giant artificial particle cloud to test safety device.}

\section{BY ALEXANDRA WITZE}

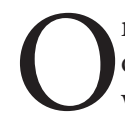
n 28 October, if all is calm and clear off the west coast of France, Fred Prata will help to simulate a near-disaster. Prata, an atmospheric scientist at Nicarnica Aviation in Kjeller, Norway, has planned the biggest field test yet for a device intended to help aeroplanes to survive close encounters with volcanic ash, which can melt in the high temperatures of jet engines and form a glassy coating that chokes airflow.

Instead of an actual erupting volcano, Prata and his team have a tonne of ash, flown in his efforts at Nicarnica, an offshoot of the Norwegian Institute for Air Research. This month's test could be a major step towards getting the sensor onto commercial jets worldwide.

The work highlights how much scientists have learned about volcanic ash since Eyjafjal lajökull brought much of Europe to its knees. The eruption "brought different disciplines together in ways that weren't integrated before", says Sue Loughlin, head of volcanology for the British Geological Survey in Edinburgh, UK. "That's been a really great thing." What these researchers learned has led European regulators to devise new guidelines on how much ash is acceptable for planes to fly through. And scientists have improved their understanding of how the spread of ash over long distances is affected by factors such as weather patterns.

Prata's sensor, the Airborne Volcanic Object Imaging Detector (AVOID), uses infrared cameras to detect the silicate particles in volcanic ash. In 2011, it flew in successful low-elevation tests at Italy's erupting Etna and Stromboli volcanoes. The upcoming experiment will involve the largest artificial ash cloud ever made, and will probably be over the Bay of Biscay, in airspace controlled by the French military. (There is a backup site on France's Mediterranean coast in case of bad weather.)

An Airbus A400M cargo plane will fly in a tight spiral, dispensing ash from 50 barrels as it climbs from 3,000 metres to almost 4,000 metres (see 'Silver lining'). A second plane, an Airbus A340 commercial airliner carrying the AVOID sensor, will fly near the cloud at various heights, taking measurements. A four-seater propeller plane from the Düsseldorf University of Applied Sciences in Germany will measure optical properties from inside the cloud. Without a jet engine, this plane is not at risk of engine failure; it has previously flown in heavy ash plumes above active volcanoes, says Konradin Weber, leader of the Düsseldorf team.

At its densest, the artificial cloud is likely to contain no more than 1 milligram of ash per cubic metre, says Prata. That puts it at the low end of air contamination under European regulations adopted after Eyjafjallajökull. Anything below 0.2 milligrams is considered safe to fly in; between 0.2 and 2 milligrams, a pilot must be aware of ash hazards; between 2 and 4 milligrams, a pilot must conduct a special risk assessment to fly; and above 4, all flights are grounded.

It is not clear whether the artificial ash cloud

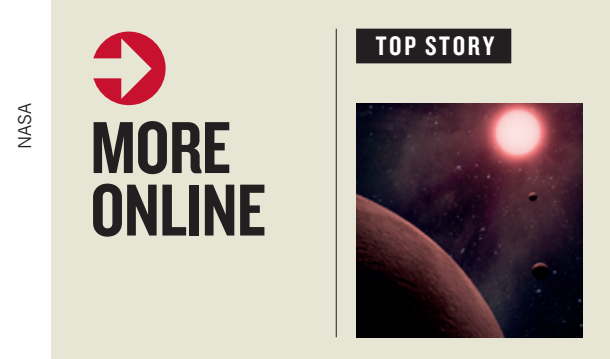

Kepler finds two exoplanets orbiting at a steep angle to their star's equator go.nature. com/liu2bd

\section{MORE NEWS}

- HIV vaccine raised infection risk go.nature.com/a36gz4

- Spain saves research council from imminent bankruptcy go.nature.com/gesitc - Fossil skull suggests that Homo erectus should subsume two other hominin species go.nature.com/b4gnpl

\section{NATURE PODCAST}

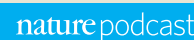

Reading minds by decoding brains; the truth about T. rex; and the week's top news in science nature. com/nature/podcast 


\section{SILVER LINING}

Scientists will create an artificial ash cloud over the Bay of Biscay off France, to test a sensor designed to help planes avoid ash that can foul jet engines.

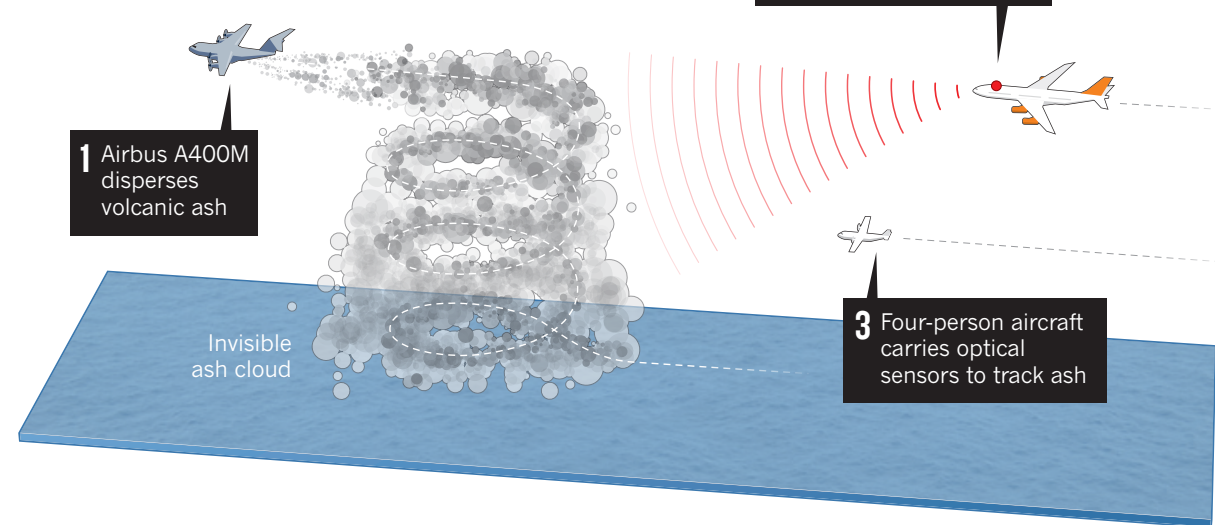

will be visible to the human eye, although scientists on a German research jet did spot Eyjafjallajökull ash in 2010, at concentrations below 0.2 milligrams of ash per cubic metre (U. Schumann et al. Atmos. Chem. Phys. 11, 2245-2279; 2011). The artificial cloud is likely to dissipate in 6 to 12 hours, falling out harmlessly over the ocean, says Prata. The experiment will cost roughly $€ 500,000$ (US $\$ 680,000$ ) and, he says, "We have only one shot."

The researchers will know just how much ash is released, and its precise geometry, so the experiment will provide the best test yet for AVOID. But many hurdles remain before the system can be used commercially, including the need to integrate it into a working cockpit, and to scale up production. "It's really not clear what we will do next," says Prata. The decision rests mostly with Airbus, which would need to decide whether to develop the technology further. Prata hopes that AVOID could one day be used on planes flying in volcanically active regions from Indonesia to Chile or Alaska.

Back where it all began, a major initiative called FUTUREVOLC is focusing on improving monitoring of Icelandic volcanoes. Led by the University of Iceland in Reykjavik and the Icelandic Meteorological Office, researchers are beefing up networks of equipment including seismic stations, cameras and gas detectors. "We're working on all aspects, from magma generation inside the crust to how it progresses into eruption plumes and how this is dispersed," says Freysteinn Sigmundsson, an earth scientist at the University of Iceland and co-coordinator of the project.

Even Prata is involved in FUTUREVOLC: he plans to deploy three of Nicarnica's infrared cameras on the ground in Iceland. They will measure how fast and how high ash plumes rise - on their way to disrupting airspace somewhere.

\section{CORRECTIONS}

The News story 'Study aims to put IPCC under a lens' (Nature 502, 281; 2013) said that Jean-Pascal van Ypersele was at the Catholic University of Leuven. He is at the Catholic University of Louvain in Louvainla-Neuve. The Editorial 'The maze of impact metrics' (Nature 502, 271; 2013) wrongly located the University of North Texas - it is in Denton, Texas. 